\title{
The Impact of Multi-Dimensional Urbanization on China's Carbon Emissions Based on the Spatial Spillover Effect
}

\author{
Zhi-Qiang Sun ${ }^{1,2}$, Tao Sun ${ }^{1 *}$ \\ 'College of Economics and Management, Nanjing University of Aeronautics and Astronautics, Jiangsu, Nanjing, China \\ ${ }^{2}$ Jincheng College, Nanjing University of Aeronautics and Astronautics, Jiangsu, Nanjing, China
}

Received: 13 October 2019

Accepted: 21 November 2019

\begin{abstract}
This paper used the panel data of 30 provinces in China from year 2006 to 2018 to calculate the carbon emissions of each province. Moran's I index is used to measure and analyze the spatial autocorrelation of carbon emissions among the provinces in China. The study considered three dimensions of urbanization such as population urbanization, land urbanization and economic urbanization to empirically analyze their effects on carbon emissions. In addition, spatial spillover effects were also explored. The main conclusions are as follows: (1) There is a positive spatial correlation between carbon emissions in China's provinces, and Moran's I index is greater than 0.5, indicating a significant correlation of carbon emissions; (2) in the context of three dimensions of urbanization, the direct effects are significant and positively influence regional carbon emission levels. Moreover, the indirect effects of population urbanization and land urbanization on regional carbon emissions are negative and coefficients are large. Whereas, the indirect effects of economic urbanization are small and insignificant. The total effect of population urbanization and economic urbanization are significantly positive and the total effects of land urbanization are found to be negative. (3) Environmental regulation and energy consumption structure as the control variables have a greater impact on carbon emissions, and the coefficient of the total effect is positive. Whereas, foreign direct investment and industrial structure have less impact and spatial spillover effects are not obvious.
\end{abstract}

Keywords: urbanization, carbon emissions, spatial effects, spillover effects

\section{Introduction}

Since the United Nations signed the Framework Convention on Climate Change in 1992, global warming has gradually become one of the key issues of concern

*e-mail:suntaonuaa@163.com for countries in the process of economic and social development. China, as the world's largest developing country and in its current its economy is in a phase of transition from rapid growth of high quality economic development. Similarly, in this process, the country is facing tremendous pressure on energy conservation and emission reduction. Historical data indicate that since 2007, China surpassed the United States to become 
the world's largest carbon emitter. Consequently, the growing carbon emissions have drawn wide attention from the international community. Following the roadmap of Kyoto convention and the pressure to reduce carbon emission, the Chinese government has promised in 2005 meeting that China will reduce carbon intensity by $40 \%$ to $45 \%$ by 2020 . In addition, at the 2015 Paris Climate Conference, it was again promised that by 2030 , carbon emissions will fall by $60 \%$ to $65 \%$ on the basis of 2005. Carbon dioxide emissions will touch the lowest point until around 2030 and strive to reach bottom as early as possible [1]. In addition, China plans to reduce its carbon dioxide emissions per unit of GDP by $18 \%$ by 2020 compared with the data of 2015 . From 1978 to 2016, China's urbanization rate increased from $17.9 \%$ to $57.35 \%$. The promotion of urbanization accelerated the population from rural to urban agglomeration. The land using pattern changed from forest land to cultivated land, industrial and commercial land. Similarly, if we look upon the industrial structure, then we can see that the industry has changed to the secondary and tertiary industries [2]. The external economies of scale and agglomeration carried out by the aforementioned changes have greatly promoted economic development. However, urban areas have created nearly two-thirds of the world's material wealth and they also emit $75 \%$ of the world's total carbon dioxide. Similarly, it produces $80 \%$ of the world's environmental pollution [3]. The relationship between carbon emissions and urbanization in the context of high-quality economic development and sustainable development has become an attractive avenue of research for the academic community.

At present, most scholars believe that there is a long-term equilibrium relationship between urbanization and carbon emissions [4]. In contrast, some scholars believe that carbon emissions are mainly generated in urban areas where population, industry, construction, and transportation are relatively concentrated. Further, the promotion of urbanization will lead to additional agglomeration of large-scale population and economic activities, and the demand for transportation will continue to rise, thus increasing energy consumption and carbon emissions [5]. However, some scholars believe that the promotion of urbanization, on the one hand, increases the density of cities, shortening the distance between work, residence, living and consumption areas, thereby reducing transportation energy consumption and reducing carbon emissions [6]. On the other hand, more and more people enjoy higher quality education, improve the quality of living for the population, and promote the accumulation of human capital. Similarly, human capital drives the sustained economic growth. However, the economic growth mode has not yet fully transformed into green intensive development. The expansion of economic activities will lead to an increase in the use of energy and an increase in carbon emissions. The impact of human capital on carbon emissions depends mainly on the role of human capital and physical capital in economic development. Only when the main driving force of economic growth is human capital rather than physical capital, then human capital growth can inhibit carbon emissions [7]. Some scholars have used data from different regions and different stages to find that urbanization has a nonlinear or phased difference in carbon emissions, and they argued that there is an inverted U-shaped relationship between urbanization and carbon emissions [8-10].

In fact, the factors affecting carbon emissions are very complex and involve many levels of investigation. Carbon emissions are the result of a combination of factors including urbanization [11]. Scholars have used different factors affecting carbon emissions according to diverse research objectives. However, from the perspective of population size, one view is that the growth of population size increases the occupational area of forest land and cultivated land. Likewise, increasing the living area of cultivated land can promote the growth of household energy consumption which can increase carbon emissions [12]. Moreover, some studies have highlighted that other factors are more important drivers of growing carbon emissions compared to population size [13]. There is also a view that urbanization has changed the traditional way of agricultural production, which means that the mode of production has changed from the traditional self-sufficient agricultural production mode to specialized large-scale production. Consequently, the non-agricultural industry has caused the migration of production and living space. In this process, the secondary industry and the service industry continue to concentrate on the city. Therefore, population and other factors of production continue to gather in cities, and the demand for secondary and tertiary industries increases, thereby contributing to carbon emissions [14]. As far as the level of economic development is concerned, it is mainly reflected in GDP or per capita disposable income. Some studies indicate that the development of the economy has increased the energy consumption capacity of enterprises and residents, thus promoting the increase of carbon emissions [15]. It is generally believed that when the level of economic development is high enough, the emphasis will be more toward technological innovation. Likewise, industrial production will gradually become technology driven and lower carbon emissions, which will obviously help to reduce carbon emissions [16]. As far as the technical level is concerned, the research conclusions are basically the same which highlight that the improvement of the technical level can promote the improvement of energy use efficiency and thus contribute to carbon emission reduction.

Summing up the discussion, it can be stated that the impact of urbanization on carbon emissions has attracted the attention of a large number of scholars those have produced a valuable knowledge. However, there are still some shortcomings in the existing research that are mainly reflected in the following aspects. First, 
the connotation of urbanization is very comprehensive, it is not only the flow of the rural population to urban population that has been remained the interest of previous studies. Although, previous researches used construct urbanization, but these studies tried to cover urbanization from one aspect only and lacks to include other aspects such as urbanization of land and the urbanization of the economy. This study addresses the shortcomings of existing studies and used urbanization from three aspects such as population urbanization, land urbanization and economic urbanization. Second, from the perspective of the research method used, previous studies generally used traditional econometric methods, assuming that the provinces are independent of each other. This study doesn't considered spatial correlation and spatial spillovers effects. Our studies also address this research gap and construct a spatial panel model from three dimensions of urbanization. The study considers spatial effects and discusses the influencing factors of carbon emissions and their differences under different urbanization dimensions.

\section{Methods}

\section{Spatial Autocorrelation Analysis}

Spatial autocorrelation refers to the interdependence of variables in spatial dimensions. In reality, objects are related to each other; however, some objects with close distances are more closely related compared with the objects with high distances. Similarly, this correlation is called spatial dependence. This spatial dependence is widely used in academic research and it is also applicable for economics research. A large number of studies in economic literature have indicated that various economic phenomena's are interrelated and not completely independent. This correlation is generally measured by the statistic Moran's I in spatial econometrics. The Moran Index was proposed by Australian statistician Patrick Alfred Pierce Moran (1950) [17]. The indexed is expressed as follows:

$$
\begin{gathered}
\text { Moran's } I=\frac{\sum_{i=1}^{n} \sum_{j=1}^{n} W_{i j}\left(Y_{i}-\bar{Y}\right)\left(Y_{j}-\bar{Y}\right)}{S^{2} \sum_{i=1}^{n} \sum_{j=1}^{n} W_{i j}} \\
W_{\mathrm{ij}}=\left\{\begin{array}{cc}
1 & \text { Area } \mathrm{i} \text { and area } \mathrm{j} \text { are adjacent } \\
0 & \text { Area } \mathrm{i} \text { and area } \mathrm{j} \text { are not adjacent }
\end{array}\right.
\end{gathered}
$$

Where $Y_{i}, Y_{j}$ represent observations for the i-th or $\mathrm{j}$-region, and $\mathrm{n}$ represents the number of regions. Moran's I index reflects the spatial correlation of spatially adjacent inter-regional variables. The value of the index usually remains between -1 and 1 . In a situation, when the value of index is greater than 0 , it means that the observed variables have positive correlation. Similarly, the positive and the larger value mean a strong and positive correlation which highlights the stronger similarity between adjacent units. When the value is equal to 0 , it means that there is no correlation between the observed variables. On the other hand, when the value is less than 0 , it means that there is a negative correlation between the observed variables. Therefore, the smaller value indicates the strong negative correlation which means greater the differences between adjacent units.

\section{Space Panel Measurement Model}

The study of spatial econometric models includes spatial effects in both spatial autocorrelation and spatial variability. Spatial autocorrelation means spatial dependence which mainly refers to the lack of independence of observations in space. Further, absolute and relative position determines the degree of correlation and mode of space. Spatial difference refers to the space caused by the heterogeneity of spatial units which indicate that the effect is inconsistent at the regional level. Spatial econometric analysis includes Spatial Lag Model (SLM), Spatial Error Model (SEM) and Spatial Durbin Model (SDM). The spatial lag model (SLM) explores whether each variable has a dispersion phenomenon (i.e. the spillover effect) in a certain area. The spatial dependence is reflected in the lag term of the dependent variable. The spatial dependence of the spatial error model (SEM) exists in the disturbance term. In a context of the error term, it mainly measures the influence of the error of the dependent variable on the observed value of the dependent variable in the neighborhood. The spatial Dubin model (SDM) not only examines the spatial correlation of dependent variables, but also the spatial correlation of the independent variables. Consequently, the spatial dependence effect is not only affected by the variables in the region, but also the interaction of inter-regional variables and the interaction of error terms with autocorrelation [18]. Keeping in mind the scope of this study, the spatial Dubin model (SDM) is selected and the model is developed as the Equation (1):

$$
\mathrm{Y}=\alpha l_{n}+\rho W Y+\beta X+\theta W X+\varepsilon
$$

Where: $\mathrm{W}$ is the spatial weight matrix, WY represents the influence of the dependent variable of the adjacent region on the dependent variable of the region, $\beta$ is the coefficient of the independent variable, $\rho$ is the coefficient of the spatial lag term, and WX represents the space of the adjacent region independent variable to the influence of local dependent variable, $\theta$ is the coefficient of the lag term of the independent variable space. When $\theta=0$, the SDM model is transformed into an SLM model;

When $\theta+\rho \beta=0$, the SDM model is transformed into an SEM model. 
Since the spatial panel data has both spatial characteristics and time characteristics, the error terms of the SDM model is decomposed to obtain the Equation (2):

$$
\mathrm{Y}=\alpha l_{n}+\rho W Y+\beta X+\theta W X+\mu_{n}+\mu_{t}+\varepsilon
$$

Among them: $\mu_{n}$ represents the time fixed effect, and $\mu_{n}$ represents the spatial fixed effect, which is a random effect when neither exists. The fixed effect model can be divided into time fixed effect, a spatial fixed effect and the two-way fixed effect.

The dependent variable $\mathrm{Y}$ used in this paper is the carbon emission intensity. The explanatory variables $\mathrm{X}$ used are population urbanization, land urbanization, economic urbanization. Control variables are environmental regulation, energy consumption structure and foreign direct investment. Specific indicators used for each variable are described below.

\section{Decomposition Method of Space Spillover Effect}

In order to explain the regression coefficients of the spatial econometric model, Lesage and Pace (2010) proposed a partial differential method for spatial regression models [19]. Based upon their approach, first their model can be written as:

$$
\begin{gathered}
\left(I_{n}-\rho W\right) Y=\alpha l_{n}+\beta X+\theta W X+\varepsilon \\
\mathrm{Y}=\sum_{r=1}^{k} S_{r}(W) X_{r}+V(W) l_{n} \alpha+V(w) \varepsilon \\
S_{r}(W)=V(W)\left(I_{n} \beta_{r}+W \theta_{r}\right)
\end{gathered}
$$$$
\mathrm{V}(W)=\left(I_{n}-\rho W\right)^{-1}=I_{n}+\rho \mathrm{W}+\rho^{2} W^{2}+\rho^{3} W^{3}+\cdots
$$

In the Equation (3-6), $\mathrm{k}$ represents the number of explanatory variables, where $\mathrm{Xr}$ represents the $\mathrm{r}$-th explanatory variable $(\mathrm{r}=1,2, \ldots, \mathrm{k})$, represents the n-order identity matrix, $\theta \mathrm{r}$ represents the estimated coefficient of the $r$-th variable of WX, $\beta r$ represents the regression coefficient of the $\mathrm{r}^{\text {th }}$ explanatory variable in variable $X$. In addition, to further clarify the effect of $\operatorname{Sr}(\mathrm{W})$, this paper rewrites the Equation (4) into the Equation (7), and $Y_{i}$ in a certain region $i$ $(\mathrm{i}=1,2, \ldots, \mathrm{n})$ can be expressed as in Equation (8). According to this, it can be seen that the $Y_{i}$ is biased to the $\mathrm{r}$-th explanatory variable. Therefore, the $\mathrm{Xjr}$ of other regions $j$ is used to obtain the Equation (9). In addition, the same mechanism is used to obtain Equation (10):

$$
\begin{aligned}
& \left(\begin{array}{c}
Y_{1} \\
Y_{2} \\
M \\
Y_{n}
\end{array}\right)=\sum_{r=1}^{k}\left(\begin{array}{cccc} 
& & & \\
s_{r}(W)_{11} & S_{r}(W)_{12} & \cdots & S_{r}(W)_{1 n} \\
S_{r}(W)_{21} & S_{r}(W)_{22} & \cdots & S_{r}(W)_{2 n} \\
\cdots & \vdots & \vdots & \vdots \\
S_{r}(W)_{n 1} & S_{r}(W)_{22} & \cdots & S_{r}(W)_{k n}
\end{array}\right)\left(\begin{array}{c}
X_{1 r} \\
X_{2 r} \\
\vdots \\
X_{k r}
\end{array}\right) \\
& +V(W) l_{n} \alpha+V(W) \varepsilon
\end{aligned}
$$

$$
\begin{gathered}
Y_{i}=\sum_{r=1}^{k}\left[S_{r}(W)_{i 1} X_{1 r}+S_{r}(W)_{i 2} X_{2 r}+\cdots S_{r}(W)_{i k} X_{k r}\right] \\
+V(W) l_{n} \alpha+V(W) \varepsilon
\end{gathered}
$$

$$
\begin{aligned}
\frac{\partial Y_{i}}{\partial X_{j r}} & =S_{r}(W)_{i j} \\
\frac{\partial Y_{i}}{\partial X_{i r}} & =S_{r}(W)_{i i}
\end{aligned}
$$

$\mathrm{S}_{\mathrm{r}}(\mathrm{W})_{\mathrm{ij}}$ in the above formula is mainly used to measure the influence of the interpretative variable of region $i$ by the $r$-th explanatory variable in region j. Compared with the OLS estimation coefficient, if $j$ and $\mathrm{r}$ are not equal in the spatial regression model, the partial derivative of Yi to Xjr is generally not 0 , and its value is determined by the $\mathrm{i}$-th and $\mathrm{j}$-th elements in the matrix $\operatorname{Sr}(\mathrm{W})$. In addition, the partial derivative of $\mathrm{Yi}$ to $\mathrm{Xir}$ is generally not equal to $\beta \mathrm{r}$. Therefore, changes in explanatory variables in a certain region will not only affect the explanatory variables in the region, but also affect the explanatory variables in other regions. Combined with the view put forward by Lesage and Pace (2010) [19], $S_{r}(W)_{i j}$ is the direct effect. It means that the explanatory variable has an overflow effect in the region of the explanatory variable. Further, $S_{r}(W)_{i j}$ is the indirect effect which means there is a spillover effect of the inter-interpretive variable of the interpretative variable that is basically the total effect and is the sum of the two.

\section{Variable Selection and Indicator Interpretation}

\section{Interpreted Variables}

Carbon intensity (CI), if the total amount of carbon emissions is used as a measure of carbon emission levels, it will result in large uncontrollable differences due to differences in economic development across provinces. Therefore, in this paper, the indicator is obtained by dividing the total carbon emissions of the region by the GDP of the region.

The calculation formula for the total amount of carbon emissions is as follows:

$$
C_{i t}=\sum_{j=1}^{8} Q_{i j t} \eta_{j} \gamma_{j}
$$

Among them, $C_{i t}$ is the total carbon emission in the t-year of i province; $Q_{i j t}$ is the consumption of $\mathrm{jth}$ energy in the t-year of i province; $\eta_{j}$ is the standard coal coefficient of $j$-th energy; $\gamma_{j}$ is the $j$-th energy carbon emission coefficient. The standard coal coefficient and the carbon emission coefficient of various energy sources are shown in Table 1.

\section{Explanatory Variables}

According to its connotation, urbanization is divided into four dimensions: population urbanization, land 
Table 1. Various energy standard coal coefficient and carbon emission coefficient.

\begin{tabular}{|c|c|c|}
\hline Energy variety & $\begin{array}{c}\text { Standard coal } \\
\text { coefficient } \\
\text { (kg standard coal) }\end{array}$ & $\begin{array}{c}\text { Carbon emission } \\
\text { coefficient } \\
\text { (t carbon / tce) }\end{array}$ \\
\hline Coal $(\mathrm{kg})$ & 0.7143 & 0.7467 \\
\hline Diesel $(\mathrm{kg})$ & 1.4571 & 0.5913 \\
\hline Gasoline $(\mathrm{kg})$ & 1.4714 & 0.5532 \\
\hline Kerosene $(\mathrm{kg})$ & 1.4714 & 0.3416 \\
\hline Crude $(\mathrm{kg})$ & 1.4286 & 0.5854 \\
\hline Fuel oil $(\mathrm{kg})$ & 1.4286 & 0.6176 \\
\hline Coke $(\mathrm{kg})$ & 0.9714 & 0.1128 \\
\hline Electric power $(\mathrm{kw} . \mathrm{h})$ & 0.1229 & 2.2132 \\
\hline Natural gas $\left(\mathrm{m}^{3}\right)$ & 1.3300 & 0.4479 \\
\hline
\end{tabular}

Source: China Energy Statistical Yearbook 2017 and IPCC Guidelines for National Greenhouse Gas Inventories (2006).

urbanization, economic urbanization (the process of economic structure that is not related to agriculture) and social urbanization (mainly refers to the diffusion of urban culture, lifestyle and value perspective).

Population Urbanization (PU). In the process of urbanization of population, in the context of the energy structure with fossil energy, the increase in household consumption due to increase in urbanization drives the growth of energy consumption and it directly promotes the carbon dioxide emissions. With the continuous improvement of the living standards of urban residents, now, they have a high pursuit of quality of life such as production, living and consumer demand. These species are important sources of carbon dioxide emissions which directly lead to an increase in carbon emissions from living energy. The specific calculation method of population urbanization in this paper is the number of urban population at the end of the year divided by the number of permanent residents in the region.

Land Urbanization (LU). The transformation of land use patterns caused by the process of land urbanization is also considered to be one of the main factors affecting carbon emissions. The first aspect is land as a natural carrier of ecosystems. The important impact is mainly the process of transforming land use types into secondary and tertiary industries. Compared with the primary industry, the secondary and tertiary industries are characterized by high energy consumption. Therefore, land urbanization promotes the increase of carbon emissions. The second aspect is land as a carrier of urban development, supporting social production and human activities. Thus, the increased production and living of human beings in cities and towns has increased carbon emissions. In this study, the specific calculation method of land urbanization is used as the area of urban built-up divided by administrative area.
Economic Urbanization (EU). Economic urbanization is a process of continuous changes in industrial structure, its optimization and upgrading of industrial structure. Changes in industrial structure will directly affect energy demand and change the structure of energy consumption [4]. Therefore, we believe the different industrial structure has the distinguished impact on carbon emissions. Specifically, the energy consumption of the secondary industry is much higher than that of agriculture and the tertiary industry, particularly high-energy consuming and high-pollution industries are dominated by heavy industries. In the case of the same output, its energy consumption is much higher than other industries. Therefore, it can be stated that more carbon dioxide will be emitted. Different from the increase in the amount of urbanization pursued by the secondary industry, the tertiary industry refers to knowledge-intensive and labor-intensive industries represented by the service industry [5]. For example, low-carbon emission electronics and bio-industry are all focused on improving urbanization quality. The industry's energy consumption is lower than that of the secondary industry. With the advancement of urbanization, the industrial structure has been fully transformed and upgraded, and the tertiary industry has dominated the economy, and urban carbon emissions have gradually decreased. This paper uses the proportion of the tertiary industry to represent economic urbanization.

Compared with the other three types of urbanization, social urbanization mainly points to the ideological level, and it is difficult to select quantitative indicators. Based on this, the paper studies the impacts and differences of carbon emissions in the three dimensions of population urbanization, land urbanization and economic urbanization.

\section{Control Variables}

Energy consumption structure (EC).China is the world's second largest energy producer and consumer. The main energy source is still coal, therefore, it can be said that the main ingredient of the energy structure in China is coal. Moreover, coal is recognized as the most important factor in carbon emissions. Thus, this paper expresses the energy consumption structure by the proportion of regional coal consumption in total energy consumption.

Foreign direct investment (FDI). FDI has an impact on regional environmental quality and resource consumption through technology spillover effects, scale effects and industrial structure effects. Therefore, it is generally believed that FDI affect carbon emission levels. This paper chooses the proportion of foreign direct investment in the regional GDP as the basis for evaluating the degree of regional economic openness. The amount of foreign direct investment is calculated by converting the US dollar to the RMB at the exchange rate. 
Table 2. 2006-2018 Carbon Emissions Moran's I Index Statistics.

\begin{tabular}{|l|l|l|}
\hline \multirow{2}{*}{ Year } & \multicolumn{2}{|c|}{ OFDI } \\
\cline { 2 - 3 } & Moran & P-value \\
\hline 2006 & 0.5112 & 0.0010 \\
\hline 2007 & 0.5034 & 0.0003 \\
\hline 2008 & 0.5512 & 0.0011 \\
\hline 2009 & 0.5034 & 0.0009 \\
\hline 2010 & 0.5316 & 0.0012 \\
\hline 2011 & 0.5019 & 0.0014 \\
\hline 2012 & 0.5176 & 0.0011 \\
\hline 2013 & 0.5233 & 0.0004 \\
\hline 2014 & 0.5245 & 0.0013 \\
\hline 2015 & 0.5278 & 0.0004 \\
\hline 2016 & 0.5363 & 0.0004 \\
\hline 2017 & 0.5378 & 0.0009 \\
\hline 2018 & 0.5344 & 0.0016 \\
\hline
\end{tabular}

Environmental Regulation (ERI). It mainly refers to the government adopting some incentive measures, such as increasing the cost of production and transaction by collecting taxes and fees on energy producers and energy consumers, thereby reducing the production of fossil energy carbon emissions, or the use of imperative regulatory measures. In addition, under the pressure of current environmental regulations, the owners of fossil energy will not only reduce their own business activities, but will instead harvest fossil energy faster and on a larger scale. This behavior will lead to an increase in fossil energy demand and promote carbon emission reductions, which are also the indirect effects of environmental regulations on carbon emissions. This paper selects the proportion between the sewage charge collection in each industry and the regional GDP to reflect the intensity of environmental regulation.

The basic unit of research in this paper is the carbon emission intensity of 30 provinces (municipalities and autonomous regions) in the country from 2006 to 2018. Due to the limitations of the availability of data, this study don't use the data of the Tibet Autonomous Region, Taiwan, Hong Kong and Macao Special Administrative regions. In the process of calculating the carbon emissions of fossil energy, the data includes the primary energy consumption of diesel, kerosene, gasoline, fuel oil, crude oil, natural gas, electricity and coal in the various provinces of China. This data is mainly gathered from the China Energy Statistical Yearbook (2006-2018); cement production and regional GDP data are taken from the China Statistical Yearbook (2006-2018). Among them, the GDP data was adjusted to the constant price level in 2006.

\section{Results and Discussion}

\section{Spatial Correlation Analysis Results}

This paper introduces the Rook first-order adjacency weight matrix. The carbon emission data used in this study were derived from the aforementioned methods. The results of the global Moran's I index using GeoDa software are presented in the Table 2.

It can be seen from the results presented in the Table 2 that Moran's I index of carbon emissions is positive and the magnitude is greater than 0.5 . Similarly, it indicate that there is a strong positive correlation between regional carbon emissions. Thus, it can be argued that regional carbon emissions are not only affected by the factors of the region, but the development, urbanization process and industrial planning in surrounding areas also influence carbon emissions in the region. Therefore, it is necessary to fully consider the existence of spatial effects.

\section{Model Test Results}

First, it is necessary to determine whether to use random or fixed effects. Therefore, to do so a Hausman test [20] was employed, and the test results show that the statistic is 66.3571, Prob. $=0.0001$. The value is significant which means we have found evidence to reject the null hypothesis. Therefore, a fixed effect model can be used.

Second, SLM and SEM [21] models need to be tested to determine which results are more suitable. Similarly, this paper used the hypothesis test of spatial correlation maximum likelihood estimation, LM hysteresis test, LM error test, Robust LM hysteresis test and Robust LM error test method to find which one is suitable. The test results are shown in the Table 3.

Table 3. LM test.

\begin{tabular}{|c|c|c|c|c|}
\hline LM test & No space effect & Spatial fixation effect & Time fixed effect & Double fixed effect \\
\hline LMHysteresis test & $166.2231^{* * *}$ & $133.9811^{* * *}$ & $129.0921^{* * *}$ & $77.7765^{* * *}$ \\
\hline RobustLM Hysteresis test & $5.0121^{* *}$ & $17.7671^{* * *}$ & $9.0431^{* * *}$ & 2.0871 \\
\hline LM Error test & $128.2083^{* * *}$ & $103.7761^{* * *}$ & $115.7609 * * *$ & $98.3873^{* * *}$ \\
\hline RobustLMError test & $8.9911^{* * *}$ & $3.4568^{* *}$ & $5.0241^{* *}$ & $43.9128 * * *$ \\
\hline
\end{tabular}


Table 4. Wald test.

\begin{tabular}{|c|l|}
\hline Wald Hysteresis test & $35.8872^{* * *}$ \\
\hline Wald Error test & $34.2231^{* * *}$ \\
\hline
\end{tabular}

It can be seen from Table 3 that the LM test and the Robust LM test under the spatial fixed effect, the time fixed effect and the double fixed effect mostly pass the significance test. In addition, both the LM hysteresis test and the LM error test are significant at the $1 \%$ level. It indicates that the spatial lag model and spatial error model which one from both can be used to better analyze the problem. Lesage and Pace pointed out that it is more appropriate to use an SDM model with a universal form of the spatial panel model for analysis. Moreover, to determine which model of SLM, SEM and SDM is more suitable, Wald test [22] give indication such as if the $\mathrm{P}$ values of the Wald lag test and the Wald error test are significant, and then the SDM model is used. In contrast, if the $\mathrm{P}$ values of these two tests are insignificant, then the LM lag test and the LM error test is applied. Significant results of LM test indicate SLM model can be used. Otherwise, if the LM error test gives a significant result, it means SEM should be used. If the two test results point to the opposite, SDM is used. The results of the test are shown in the Table 4.

It can be seen from the results given in the Table 4 that a spatial Dubin model with fixed effects should be established. Similarly, we have established a spatial Dubin model with fixed effects.

\section{Analysis of Spatial Dubin Model under Fixed Effect}

\section{Fixed-Effect SDM Model}

This paper used MATLABR software for spatial panel model analysis. According to the previous analysis and discussion, the SDM model with fixed effect is found to be suitable for this study. The estimated results are shown in the Table 5.

As it can be seen from Table 5, the results of SDM are more ideal due to several reasons. First, $\mathrm{R}^{2}$ is greatly improved compared to the non-spatial panel model. Secondly, the degree of dispersion $\sigma^{2}$ of the model is also reduced relative to the non-spatial panel model. Finally, the significance of the space ( $\mathrm{W}^{*}$ dep. var.) indicates that the space spillover effect is obvious. Therefore, it can be stated that SDM can improve the effectiveness of the estimate.

In the SDM analysis, the time fixed effect; the spatial fixed effect and the two-way fixed effect are compared. It can be seen that the two-way fixed effect $\mathrm{R}^{2}$ and $\sigma^{2}$ are superior to the other two fixed effects. Therefore, the two-way fixed effect model is adopted in this paper. However, due to the spatial lag term of the variable in the spatial Dubin panel model, the estimated coefficient cannot explain the degree of influence of the independent variable on the dependent variable. In addition, the estimated coefficient is only effective for the direction and significance level. Therefore, in order to measure the degree of influence of the independent variable on the dependent variable, it is necessary to further estimate the direct, indirect and total effects

Table 5: Estimation results of spatial Dubin model under fixed effects.

\begin{tabular}{|c|c|c|c|c|}
\hline Variable & No space effect & Spatial fixation effect & Time fixed effect & Double fixed effect \\
\hline $\ln \mathrm{PU}$ & $-0.2013 * * *$ & -0.0733 & $-0.3321 * *$ & -0.0431 \\
\hline $\operatorname{lnLU}$ & -0.0234 & $0.3045^{* * *}$ & -0.0922 & $0.2112 * * *$ \\
\hline $\ln E U$ & $-0.0034 * * *$ & $0.0003 * * *$ & 0.0012 & $0.0214 * * *$ \\
\hline $\operatorname{lnEC}$ & $0.1176^{* * * *}$ & $0.1345^{* * *}$ & $0.1213 * * *$ & $0.1432 * * *$ \\
\hline $\operatorname{lnFDI}$ & $0.0016^{* * *}$ & -0.0032 & 0.0122 & 0.0121 \\
\hline $\operatorname{lnERI}$ & 0.1432 & $0.1865 * * *$ & $0.2122 * * *$ & $0.2342 * * *$ \\
\hline $\mathrm{W}^{*} \ln \mathrm{PU}$ & & -0.0342 & $-0.3675 * * *$ & -0.1833 \\
\hline $\mathrm{W}^{*} \ln L U$ & & -0.0421 & -0.1532 & $-0.8521 * * *$ \\
\hline $\mathrm{W}^{*} \ln \mathrm{EU}$ & & -0.0012 & 0.0023 & $0.0016^{* * *}$ \\
\hline $\mathrm{W}^{*} \ln \mathrm{EC}$ & & 0.0532 & -0.0231 & 0.0066 \\
\hline $\mathrm{W}^{*} \ln \mathrm{FDI}$ & & $-0.0015^{*}$ & 0.0121 & 0.0404 \\
\hline $\mathrm{W}^{*} \ln \mathrm{ERI}$ & & -0.0443 & 0.3016 & $0.3561 * * *$ \\
\hline $\mathrm{W}^{*}$ dep.var & & $-0.3533 * *$ & $-0.3213 * *$ & $-0.3321 * *$ \\
\hline $\mathrm{R}^{2}$ & 0.4344 & 0.8732 & 0.4532 & 0.9998 \\
\hline$\sigma^{2}$ & 0.0451 & 0.0013 & 0.0566 & 0.0032 \\
\hline
\end{tabular}


Table 6. Two-way fixed effect SDM spatial effect decomposition.

\begin{tabular}{|c|c|c|c|}
\hline Variable & Direct effect & Indirect effect & Total effect \\
\hline $\ln \mathrm{PU}$ & $0.3422^{* * *}$ & $-0.0412^{* * *}$ & $0.3010^{* * *}$ \\
\hline $\operatorname{lnLU}$ & $0.2223^{* * *}$ & $-0.3213^{* * *}$ & $-0.0990^{* * *}$ \\
\hline $\operatorname{lnEU}$ & $0.0413^{* * *}$ & -0.0521 & $-0.0108^{* * *}$ \\
\hline $\operatorname{lnEC}$ & $0.1421^{* * *}$ & -0.0134 & $0.1287^{* * *}$ \\
\hline $\ln \mathrm{PDI}$ & $0.0115^{* *}$ & 0.0876 & $0.0991^{*}$ \\
\hline $\operatorname{lnERI}$ & $0.1633^{* * *}$ & $0.4657^{* * *}$ & $0.6290^{* * *}$ \\
\hline
\end{tabular}

of the model. The direct effect refers to the mean value of carbon emission changes in the region caused by changes in the factors affecting carbon emissions in the region. The indirect effect refers to the impact of carbon emissions influencing factors on carbon emissions in neighboring provinces. The total effect is the sum of direct and indirect effects.

\section{SDM Model Spatial Effect Decomposition Analysis}

Based on the two-way fixed-effect SDM estimation, this study spatially decomposes the effects of various factors affecting carbon emission intensity. The results are shown in the Table 6.

Furthermore, from the perspective of population urbanization, the direct effect of population urbanization is positive and significant at the 5\% level of significance. Therefore, it can be stated that for every $1 \%$ increase in population urbanization, the impact on carbon emissions in the region is $0.3422 \%$. It basically explains that the continuous expansion of the population has increased the level of carbon emissions. Moreover, the indirect effects of population urbanization are significant with negative coefficient. It indicates that urbanization has significant spatial spillover effects on economically adjacent provinces. The possible explanation is that if the urbanization of the population in neighboring regions is rapid, it will make the region industry's development in neighboring regions which may had curbed carbon emissions in the region. In addition, we found that the urbanization of the population mainly affects the intensity of carbon emissions in the region through direct effects. The overall effect is positive which indicates that the overall urbanization of the population will exert excessive pressure on carbon emissions.

From the perspective of land urbanization, the results indicate that the direct effect of land urbanization is 0.2223 and significant at the $1 \%$ level of significance. The indirect effect is -0.3213 , which is significant at the $1 \%$ level of significance. The total effect is -0.099 , which is also significant at the $1 \%$ level. The direct effect is positive, indicating that the urbanization of land in the region has led to an increase in land use in the region. On the one hand, the loss of green space and the reduction of vegetation have led to an increase in carbon emissions. On the other hand, based on the rise of land urbanization, production, and living energy will also increase further, leading to an increase in carbon emissions. Moreover, it is found that the impact of land urbanization on carbon emissions is still dominated by indirect effects. Therefore, it can be stated that the rapid advancement of land urbanization in a region will attract population movements in neighboring regions and, to a certain extent, slow down the urbanization of neighboring regions, leading to decline in carbon emissions in the region.

Next, from the perspective of economic urbanization, the direct effect of economic urbanization is positive and significant at the $1 \%$ level of significance. It indicates that the higher the degree of urbanization, the lower the proportion of the secondary industry and the tertiary industry, which can reduce the carbon emission level of the region. The indirect effect is not significant which means the spatial spillover effect of economic growth is not obvious, indicating that the economic growth of neighboring regions has not affected the carbon emissions of the region for the time being. From the perspective of the total effect, the results are significant. As the economic urbanization is the adjustment of the industrial structure. Thus, it can be said that still it is dominated by the secondary industry, and the level of economic urbanization is at a low level.

From the perspective of control variables, first, the direct effect of the energy consumption structure is significantly positive. The indirect effect is negative but not significant, and the total effect is significantly positive. It is very intuitive to show that the more coal consumption in a region, the greater the carbon intensity of the region. But, due to the total amount of coal is limited; therefore, an increase in coal consumption in one region reduces coal consumption in neighboring regions, and thus inhibits carbon emissions in the immediate neighborhood.

Second, the direct effect of foreign direct investment is positive, indicating that the current domestic use of foreign capital is dedicated toward the quantity not quality. Therefore, it can be argued that foreign industries are high pollution driven, high energy consumption and high emissions, leading to the negative impacts of carbon emissions. Similarly, it 
creates severe environmental challenges. The indirect effect is negative but not significant, indicating that the negative impact of foreign investment has not affected the carbon emissions in adjacent regions. The total effect is positive, but the level of significance is low, indicating that the introduction of foreign capital will increase the local carbon emission level. Though, there is a limited impact on the intensity of carbon emissions in adjacent areas.

Third, under the 5\% significance level of environmental regulation, the direct effect of environmental regulation is 0.1633 , the coefficient is significant. The indirect effect is 0.4657 , which is significant at the $1 \%$ level of significance. The total effect is 0.6290 , which is significant at the $1 \%$ level of significance. We can see that the indirect effect of environmental regulation dominates. Due to the large size of China's land area, in order to adapt to local conditions, the environmental regulation policy adopted by a region may be more inclined to emulate the environmental regulation policies of neighboring regions.

\section{Conclusions}

This paper used the panel data of 30 provinces in China from 2006 to 2018 to measure the carbon emissions of each province. The three dimensions of urbanization, including land urbanization, population urbanization and economic urbanization were selected for empirical analysis. The study used the spatial Dubin panel model to empirically analyze the effects of three dimensions of urbanization on carbon emissions and their spatial spillover effects.The main conclusions obtained are as follows:

There is a positive spatial correlation between carbon emissions in various provinces in China, and the Moran's I index is greater than 0.5. It indicates that there is a significant and positive spatial correlation between carbon emissions which means that carbon emissions between adjacent provinces are mutually influential. Whereas, it is seen from the analysis performed in this study that economic factors contribute to the spatial correlation. The said conclusion is consistent with other scholars, and both have highlighted similar significant spatial correlations [23-24].

Under the three dimensions of urbanization, population urbanization is the most influential factor on China's carbon emissions. According to the empirical relationship between income and carbon emissions, China is in the rising phase of the environmental Kuznets curve, China's carbon emissions absolute quantity and relative quantity will still increase. China will still face greater pressure on energy conservation and emission reduction in the future. It can be seen that population urbanization has a positive relationship with carbon emissions in general, which is consistent with the results of other scholars [25-26]. Under other conditions, the rapid urbanization of land has increased carbon emissions, which is coordinated with economic development and environmental protection on a regional level. The relationship between the three regions poses new challenges, which is different from the results of other scholars. For example, Xu Hengzhou and Zhang Wenjing (2016) [27] found that although there are some differences between the provinces in the eastern and central regions in terms of the quality of land urbanization at this stage. However, from the perspective of national development trends, the quality index of land urbanization has an upward trend. The reason for the difference may be that this study considers the existence of spatial effects. The impact between regions makes land urbanization significantly important for carbon emissions. Economic urbanization has a little impact on regional carbon emissions, although significant impact, but the coefficient of elasticity is small. But, the negative coefficient indicates that it already has an impact, and the regional governments need to emphasize on the development of the economy. Therefore, it is necessary to pay attention to the regional carbon emission problem. In the past, scholars' research mainly focused on land urbanization and population urbanization. There are only few researches on economic urbanization, and this is the innovation of this paper. Such as domestic scholar Wang Xing (2014) [28] found that urbanization will also have a positive impact on the industrial structure, increasing the proportion of the secondary industry, thereby increasing the level of carbon emissions, which is basically consistent with the results of this paper. Moreover, the negative coefficient indicates that China's urbanization is currently promoting industrial restructuring, still the secondary industry-based, so the performance of carbon emission levels to rise.

Under the different urbanization dimensions, there are obvious differences in the impact of various factors on carbon emissions. From the point of view of the direct effect, the population urbanization estimation coefficient is significantly larger than the other two dimensions. It indicates that the relevant factors of population urbanization have greater impact on carbon emissions. Compared with the other two dimensions, the population size under the economic urbanization dimension has the least impact on carbon emissions which may be due to the fact that urbanization in this dimension drives economic development to achieve carbon reduction.

From the indirect effect, only in the economic urbanization dimension, there is a negative impact on the carbon emissions of neighboring provinces. The indirect effects under the other two dimensions have significant negative effects which mean there is a significant spatial spillover effect. This further emphasizes the importance of regional urbanization coordinated development strategy and the necessity of regional joint governance environment. Further, it indirectly reflects the rationality of this paper using the 
spatial econometric model for estimation; this is also consistent with other scholars' research [29-30].

The direct effects of environmental regulation and energy consumption structure as the control variables are very obvious because the coefficient is high. The total effect of the two is also tested and confirmed at the $1 \%$ significance level. Therefore, it is needed to control the area carbon emission process. Pay full attention to the role of environmental regulation and the adjustment of energy consumption structure to achieve low carbon emissions. Whereas, foreign direct investment and industrial structure factors have little impact on carbon emissions, the impact is indeed there. Therefore, it is necessary for the region to make full use of its advantages in coordinated development to avoid high carbon emissions. These results are also consistent with previous studies [31-32].

\section{Limitation and Outlook}

Data is the basis of empirical research. Due to the difficulty of data acquisition, this paper only employed the provincial-level data as a research sample, which we think the limitation of this research and it bounds the study only at the provincial level. Therefore, exploring the impact of urbanization on carbon emissions from the municipal level will be an important aspect that can be the prospective avenue for future research. Further, due to the different effects of urbanization on carbon emissions at different stages of development in the regions, there are also differences in the role of urbanization in carbon emissions in different periods. This study only used data from year 2006-2018 which we think is not comprehensive enough. Thus, expanding the data set and retesting of results can be the avenue for future research to enhance reliability for policy formulation.

There are many factors affecting carbon emissions, but because of the limitations of the model on the number of variables, other indicators related to population, economy, technology, and urbanization process are not included while analyzing urbanization in the paper. The impact of carbon emissions involves the per capita GDP indicator, but there may be a certain correlation between per capita GDP and urbanization, which will have a certain impact on the results of the analysis, and it is prone to endogenous problems. Therefore, it is necessary to carry out subsequent research using a more suitable method.

\section{Acknowledgements}

This paper Supported by the Chinese National Social Science Fund: Research on Collaborative Governance Mechanism and Support Policy of Environmental Pollution in Regional Integration Development of the Yangtze River Delta (Project No.: 19BJL035).

\section{Conflict of Interest}

The authors declare no conflict of interest.

\section{References}

1. Global Ecological Environment Remote Sensing Monitoring 2018 Annual Report. http://www. scio.gov.cn/XWFBH/gbwxwfbh/xwfbh/kjb/ Document/1642602/1642602.htm,Nov 19, 2018.

2. "13 $3^{\text {th }}$ Five-Year Plan" for Controlling Greenhouse Gas Emissions http://www.gov.cn/zhengce/content/2016-11/04/ content_5128619.htm, Qct 27,2016.

3. ZHENG SQ., HUO W., CAO J. Research on Elasticity Estimation of Urban Residential Carbon Emissions and Urban Differences in China. Economic Problems Research, 9, 128, 2011.

4. WANG F., ZHOU X. Population Structure, Urbanization and Carbon Emission - Empirical Study Based on Multinational Panel Data. China Population Science, 2, 47, 2012.

5. LIDDLE B. Impact of population, age structure, and urbanization on carbon emissions/energy consumption: Evidence from macro-level, cross-country analyses. Population \& Environment, 35 (3), 286,2014.

6. NIU HL. Empirical Test of Carbon Emission Effects of Urbanization in China. Statistics and Decision, 6, 138, 2019.

7. WANG Y.N., MA M.Y., CHEN W. The Threshold Effect of Urbanization on Carbon Emission and Regional Spatial Distribution. Environmental Science and Technology, 41 (11), 171, 2018.

8. LI WD., YU JJ., LI WD. Empirical Analysis of the Impact of Urbanization on Carbon Emissions in China Based on Panel Data. Journal of Beijing Jiaotong University (Social Science Edition), 16 (2), 50, 2017.

9. XIAO Z.Y. Research on the Relationship between Urbanization Development Stage and $\mathrm{CO}_{2}$ Emission in China. China Population - Resources and Environment, 21 (12), 139, 2011.

10. WANG X. Impact of Urbanization on Carbon Emissions in China - Based on Analysis of Provincial Panel Data. Urban Problems, 7 (7), 23, 2016.

11. SU W.X., SUN R.H. Driving factors of urbanization carbon emission in typical urban agglomerations in China. Chinese Journal of Ecology, 38 (6), 1975, 2018.

12. WAN Y.Y. Urbanization and Carbon Emission: A Test Based on Heterogeneous Panel Model. Inner Mongolia Social Sciences (Chinese Edition), 35 (5),104, 2014.

13. WANG Z.Q., ZHANG H. Mechanism and Governance Framework of Carbon Emissions under Population Urbanization. Enterprise Economy, 6, 11, 2017.

14. ZHANG Y.H., ZHANG T. Science and technology innovation, urbanization and carbon emissions since the reform and opening up. China Science and Technology Forum, 276 (4), 33, 2019.

15. RAGGAD B. Carbon dioxide emissions, economic growth, energy use, and urbanization in Saudi Arabia: evidence from the ARDL approach and impulse saturation break tests. Environmental Science \& Pollution Research, 25 (12), 1, 2018.

16. CAN C., ZHEN W., Guoshu B. Life-cycle $\mathrm{CO}_{2}$ Emissions and Their Driving Factors in Construction Sector in China. Chinese Geographical Science, 29 (02), 115, 2019. 
17. DENG M., LIU QL., WU J. Spatial Analysis. Beijing: Surveying and Mapping Press, 2015.

18. ELHORST J., PAUL FS. Evidence of Political Yardstick Competition in France Using a Two-Regime Spatial Durbin Model with Fixed Effects. Journal of Regional Science, 49 (5), 931, 2010.

19. LESAGE J.P., PACE R.K. Spatial Econometric Models. Handbook of Applied Spatial Analysis. 2010.

20. HAUSMAN J.A. Specification Tests in Econometrics. Econometrica, 46 (6), 1251, 1978.

21. ANSELIN L. Lagrange multiplier test diagnostics for spatial dependence and spatial heterogeneity. Geographical Analysis, 20, 1, 1988.

22. ELHORST J.P. Matlab Software for Spatial Panels. International Regional Science Review, 37 (3), 389, 2014.

23. WANG X., QIN M. An Empirical Study on the Factors Affecting Carbon Emissions under Different Urbanization Quality - Based on Provincial Panel Data. Journal of Lanzhou University(Social Science Edition), 4, 66, 2015.

24. FAN J.S., ZHOU L. Research on Influence Mechanism and Effect of Urbanization and Real Estate Investment on Carbon Emissions. Geographical science, 4, 644, 2019.

25. LI C.X., LI G.Z. Research on energy saving and emission reduction policies of Hebei Province from the perspective of policy tools. Journal of Hebei University of Geosciences, 39 (5), 58, 2016
26. CHEN Y.L. The Threshold Effect of Urbanization on Carbon Emission: An Empirical Study of Inter-provincial Data. Journal of Southwest China Normal University (Natural Science), 42 (3), 112, 2017.

27. XU H.Z., ZHANG W.J. The causal relationship between Carbon emissions and landUrbanization quality: a panel data analysis for Chinese provinces. Journal of Cleaner Production, 137, 241, 2016.

28. WANG X. Empirical Study on the Relationship between Urbanization Process and Carbon Emission in Gansu Province. Journal of Gansu Science and Technology, 3, 4, 2014.

29. LIN B.Q., LIU X.Y. Carbon emissions in China's urbanization stage: influencing factors and emission reduction strategies. Economic Research, 8, 66, 2010.

30. ZHOU K., DAI X.W. Empirical study on the relationship between urbanization and carbon emissions in China. China's population, resources and resources realm, 4, 41, 2013.

31. WANG Y. Foreign Trade, FDI and Carbon Emissions - An Empirical Analysis Based on Data from 1995 to 2012 in Gansu Province. China Business Review, 20, 157, 2014.

32. ZHENG J.J., YU X.L. Does the introduction of FDI exacerbate China's carbon emissions? - Reanalysis based on marketization perspective. China Management Sciencev, 23 (S1), 798, 2015. 
